\title{
Improvement In Self-Reported Physical Functioning With Tiotropium/Olodaterol In Central And Eastern European COPD Patients
}

This article was published in the following Dove Press journal: International Journal of Chronic Obstructive Pulmonary Disease

Arschang Valipour,' Michael Tamm, ${ }^{2}$ Jana Kociánová, ${ }^{3}$ Valentina Bayer, ${ }^{4}$ Maria Sanzharovskaya, ${ }^{5}$ Alexey Medvedchikov, (10) ${ }^{6}$ Monika Haaksma-Herczegh, ${ }^{6}$ János Mucsi, ${ }^{7}$ Zvi Fridlender, $\mathbb{D}^{8}$ Claudia Toma, ${ }^{9,10}$ Andrey Belevskiy, ${ }^{11}$ Bohumil Matula, ${ }^{12}$ Jurij Šorli ${ }^{13}$

'Department of Respiratory and Critical Care Medicine, Karl-Landsteiner-Institute for Lung Research and Pulmonary Oncology, Krankenhaus Nord - Klinik Floridsdorf, Vienna, Austria; ${ }^{2}$ Lung Centre/Pneumology Department, University Hospital Basel, Basel, Switzerland; ${ }^{3}$ Pneumological Outpatient Department, MephaCentrum, a. s., Ostrava-Poruba, Czech Republic; ${ }^{4}$ Biostatistics and Data Sciences, Boehringer Ingelheim Pharmaceuticals, Inc., Ridgefield, CT, USA; ${ }^{5}$ Respiratory TA, Boehringer Ingelheim RCV GmbH \& Co. KG, Vienna, Austria; ${ }^{\circ}$ Medical Affairs Regional Center, Boehringer Ingelheim RCV GmbH \& Co. KG, Vienna, Austria; ${ }^{7}$ Elizabeth Nursing Home, Gödöllö, Hungary; ${ }^{8}$ Department of Internal Medicine, Hebrew University Hadassah Medical School, Jerusalem, Israel; 'Department of Pneumology, Institute of Pneumatology "Marius Nasta”, Bucharest, Romania; ${ }^{10}$ Department Of Pneumology, Carol Davila University of Medicine and Pharmacy, Bucharest, Romania;

"Department of Pulmonology, Pirogov Russian National Research Medical University, Pletnev Hospital, Moscow, Russian Federation; ${ }^{12}$ Department of Functional Diagnostics, Specialized Hospital of Saint Zoerardus, Teaching Facility of the Slovak Medical University, Nitra, Slovakia; ${ }^{13}$ Topolšica Hospital, Topolšica, Slovenia

Correspondence: Arschang Valipour Department of Respiratory and Critical Care Medicine, Karl-Landsteiner-Institute for Lung Research and Pulmonary Oncology, Krankenhaus Nord-Klinik, Floridsdorf Brünnerstrasse 68, Wien, Vienna 1210 , Austria Tel +43 I 910600

Email arschang.valipour@wienkav.at
Background: Reduced physical activity is associated with increased morbidity and mortality in patients with COPD. Studies suggest that treatment with the long-acting muscarinic antagonist tiotropium and the long-acting $\beta_{2}$-agonist olodaterol increases exercise capacity. This study assessed the effects of a fixed-dose combination (FDC) of tiotropium/olodaterol (delivered via Respimat ${ }^{\mathbb{R}}$ ) on physical functioning in patients with stable COPD in a "realworld setting".

Methods: An international, open-label, single-arm, non-interventional study conducted in nine countries measuring changes in self-reported physical functioning in COPD patients treated with tiotropium/olodaterol $5 / 5 \mu \mathrm{g}$ FDC for approximately 6 weeks. The primary endpoint was therapeutic success, defined as a minimum 10-point increase in the 10-question Physical Functioning Questionnaire (PF-10) score. Secondary endpoints included absolute change in PF-10 from Visit 1 to Visit 2, patient general condition (measured by Physician's Global Evaluation score) and patient satisfaction with the treatment and device (assessed by Patient Satisfaction Questionnaire at the end of the study period).

Results: Therapeutic success was observed in $67.8 \%$ of 7218 patients $(95 \% \mathrm{CI} 66.7,68.8)$ in the final analysis set after approximately 6 weeks of treatment with tiotropium/olodaterol. Mean change in PF-10 score between Visit 1 and Visit 2 was 16.6 points (95\% CI 16.2, 17.0). Therapeutic success was $64.3 \%(95 \%$ CI $63.0-65.6 \%)$ in patients with infrequent $(\leq 1)$ and $76.1 \%(95 \%$ CI $74.3-77.9 \%)$ in patients with frequent $(\geq 2)$ exacerbations $(\mathrm{p}<0.0001)$. Patient general condition improved as indicated by an improvement in Physician's Global Evaluation scores between visits. Most patients were very satisfied or satisfied with tiotropium/olodaterol treatment in general $(81 \%)$, reported inhalation satisfaction $(85 \%)$, and satisfactory handling of the device $(84 \%) .1 .3 \%$ of patients reported an investigator-defined drug-related adverse event.

Conclusion: Treatment with tiotropium/olodaterol led to an improvement in self-reported physical functioning in patients with COPD.

Keywords: tiotropium, olodaterol, chronic obstructive pulmonary disease, COPD, physical functioning, non-interventional study

\section{Plain language summary}

Patients with COPD are less active. This can cause a patient's quality of life to decrease, and they may need more visits to hospital. However, treatment with drugs that open the airways can help people do more exercise and improve their level of physical activity. We tested if using a combination of two of these drugs, called tiotropium and olodaterol, could help increase patients' activity levels. We also studied people's general condition and if they were 
happy with the inhaler device. We found that most patients improved their activity levels. Patients' general condition also improved, and most were satisfied with the treatment and inhaler. These results may mean that these drugs could help keep patients active and help them to stay well for longer.

\section{Introduction}

COPD affects approximately 251 million people globally. ${ }^{1,2}$ It is characterized by airflow obstruction and hyperinflation, resulting in dyspnea and exercise limitation. ${ }^{3}$ Exerciseinduced breathlessness prevents many patients from carrying out physical activity. ${ }^{4,5}$ Household chores and other daily activities are often limited, take longer to complete or are avoided altogether. ${ }^{6,7}$ Reduced physical activity in turn has been associated with muscle deconditioning, ${ }^{8}$ causing a downward spiral of exercise impairment and clinical worsening, with increased exacerbation risk and hospital admissions. ${ }^{9}$ Patients with impairments in physical activity also experience an increased healthcare resource use and costs, ${ }^{10}$ depression, and anxiety, ${ }^{11,12}$ which may further contribute to the disease burden. Furthermore, the level of deconditioning and disability has proven to be a strong predictor of mortality in patients with COPD. ${ }^{9,13}$

Inhaler therapy with bronchodilators, such as long-acting muscarinic antagonists (LAMAs) or long-acting $\beta_{2}$-agonists (LABAs), plays a central role in COPD treatment. COPD guidelines recommend LAMAs and/or LABAs as the primary maintenance treatment for COPD. ${ }^{14}$ Due to the complementary modes of action of these therapies, LAMA/LABA combination therapy can enhance the bronchodilator effect by reducing airway resistance and lung hyperinflation, and improving ventilatory muscle performance, ${ }^{15-17}$ allowing patients to exercise for longer before being limited by symptoms. ${ }^{17,18}$ This is reflected in clinical studies where patients with COPD treated with tiotropium/olodaterol dual bronchodilator therapy have shown significant improvements in exercise capacity and endurance time compared with placebo. ${ }^{15,19,20}$ While randomized controlled trials have confirmed the benefits of tiotropium/olodaterol combination therapy on exercise capacity, real-world data on physical activity are scarce. Recently, observational studies conducted in Germany demonstrated improvements in physical functioning (the ability of an individual to undertake daily tasks) ${ }^{21}$ in patients with moderate to very severe COPD using tiotropium and olodaterol. ${ }^{22,23}$

In this observational study, we aimed to measure changes in physical functioning, serving as a surrogate for physical activity and exercise capacity, in patients with COPD treated with tiotropium/olodaterol fixed-dose combination (FDC) in a real-world setting in Central and Eastern Europe. Physician-based assessment of patients' general condition, as well as patient satisfaction with tiotropium/olodaterol inhaler therapy via the Respimat ${ }^{\circledR}$ Soft Mist $^{\mathrm{TM}}$ inhaler were also assessed. In contrast to these previous, country-specific studies, this is an international study across nine countries, with varying standards of care. This study was carried out to determine whether the previously observed results were applicable to a broader patient population across different countries, healthcare settings and standards of care.

\section{Methods}

\section{Study Population}

This was an international, open-label, non-interventional study conducted in nine countries (Austria, Czech Republic, Hungary, Israel, Romania, Russian Federation, Slovakia, Slovenia, and Switzerland) between April 11, 2016 and May 4, 2017 (NCT02720757). This study was approved by the Magistrat der Stadt Wien ethics committee (EK16013VKNIS) on March 15, 2016. The study was carried out in compliance with the protocol, the principles laid down in the Declaration of Helsinki, and as close as possible to the standards of the International Conference of Harmonization Tripartite Guideline for Good Clinical Practice, Guidelines for Good Epidemiological Practice and Good Pharmacoepidemiology Practice. The sponsor of the OTIVACTO ${ }^{\circledR}$ Trial (Boehringer Ingelheim) is committed to responsible sharing of clinical study reports, related clinical documents, and patient-level clinical study data. Researchers are invited to submit inquiries via the Clinical Study Data Request website (https:// www.clinicalstudydatarequest.com).

The inclusion criteria for this study were patients aged $\geq 40$ years, with a diagnosis of COPD and requiring longacting dual bronchodilation (LAMA+LABA) treatment (according to physician-based indication and within the approved tiotropium/olodaterol label) ${ }^{24}$ and had provided written informed consent prior to participation in the study. The exclusion criteria included treatment with any LAMA/LABA combination (free- and fixed-dose) up to 6 months prior to the study or contraindications according to the approved Spiolto ${ }^{\circledR}$ label. ${ }^{24}$ To avoid double-dosing of a LABA, patients who intended to continue LABA/inhaled corticosteroid (ICS) FDC treatment were not included in 
this study. Other exclusion criteria included patients for whom further follow-up was not possible at the enrolling site during the planned study period of approximately 6 weeks; pregnancy and lactation; patients currently listed for lung transplantation; and those participating in any clinical trial or any other non-interventional study of a drug or device.

\section{Study Design}

Patients were enrolled consecutively and followed over an observational period of approximately 6 weeks, to minimize the risk of recall bias and increase patient recall accuracy. $^{25,26}$ Treatment with tiotropium/olodaterol was delivered via the inhaler device as specified by the approved Spiolto ${ }^{\circledR}$ label. Several questionnaires were used during the study; the mMRC scale (grade 0 [breathless only when I exercise] to 4 [too breathless to leave the house]) was used to assess the degree of breathlessness of the patients before treatment at baseline (Visit 1), as well as the exacerbation history and post-bronchodilator $\mathrm{FEV}_{1}$ to automatically calculate the GOLD stage in the electronic case report form. Patients were asked to complete the 10-question Physical Functioning Questionnaire (PF-10) to evaluate their physical functioning at baseline (Visit 1) and after approximately 6 weeks' treatment (Visit 2). The PF-10 is a subdomain of the validated 36-item Short Form Health Survey (SF-36) quality-of-life questionnaire. $^{27}$ It consists of 10 questions evaluating the extent of experienced restrictions while conducting everyday physical activity. Each question in the PF-10 may be answered with either "yes, limited a lot", "yes, limited a little" or "no, not limited at all", recorded on a 3-point Likert scale. Patient level of restriction is reported in the following activities: vigorous activities (eg, running, lifting heavy objects), moderate activities (eg, moving a table, swimming, pushing a vacuum cleaner or riding a bicycle), lifting or carrying groceries, climbing several flights of stairs, climbing one flight of stairs, bending, kneeling or stooping, walking more than $1 \mathrm{~km}$, walking several hundred meters, walking $100 \mathrm{~m}$, bathing or dressing yourself. The final scores from the 10 questions were summed up and standardized on a scale of 0 to 100 using the formula $100 \times($ sum-10)/20; a higher score represented better physical functioning. ${ }^{27}$ A threshold score of a 10point change in minimal important difference was selected based on a distribution-based method by Cohen. ${ }^{28}$ Patient satisfaction with the treatment, inhalation, and handling of the inhaler device was assessed at the end of the study via a patient satisfaction questionnaire on a 7-point ordinal scale, with divisions from "very satisfied" to "very dissatisfied" (Visit 2). ${ }^{29}$

Patient general condition was assessed by the Physician's Global Evaluation (PGE), an 8-point scale in which the treating physician evaluated the patient's general condition as poor (1-2), satisfactory (3-4), good (5-6), or excellent (7-8), ${ }^{22}$ both at Visit 1 and Visit 2. This was used to assess changes in patient condition from baseline to study end.

\section{Visits}

Variables were collected at both Visit 1 (baseline) and Visit 2 (after approximately 6 weeks of treatment). The following variables were recorded: demographics; history of COPD, last record of spirometric COPD severity of airflow obstruction according to GOLD (I-IV); number of overall exacerbations and number of exacerbations leading to hospitalization in the previous 12 months; history of smoking; past and present concomitant pulmonary medication; other concurrent diagnoses; other concomitant medication; breathlessness (assessed by mMRC) and tiotropium/olodaterol soft mist inhaler administration history (ie, date of first administration, training of device handling provided). The decision as to whether patients continued with tiotropium/olodaterol after the study was noted at Visit 2. Drug-related adverse events (AEs) were recorded during the time between signing of the informed consent and the end of the study.

\section{Endpoints And Assessments}

The primary endpoint was the occurrence of therapeutic success, defined as a 10-point increase in the PF-10 score, between Visit 1 (baseline) and Visit 2 (approximately 6 weeks after starting treatment). ${ }^{30}$ The secondary endpoints were changes in PF-10 score from Visit 1 (baseline) to Visit 2; patient general condition, evaluated by the physician (PGE score) at Visit 1 (baseline) and Visit 2; and patient satisfaction with therapy, assessing overall satisfaction, inhalation satisfaction and device handling at Visit 2.

\section{Statistical Analysis}

Any patient who received at least one dose of tiotropium/ olodaterol was included in the treated set (TS). Safety endpoints and demographic/baseline data were analyzed in the TS. Patients in the TS who had a PF-10 score at Visit 1 and Visit 2 comprised the full analysis set (FAS). All analyses for primary and secondary endpoints are descriptive and were performed on the FAS. For the primary endpoint, the percentage of patients with therapeutic success is presented 
together with the $95 \% \mathrm{CI}$. For the secondary endpoints (ie, the general condition of patients and patients' satisfaction with tiotropium/olodaterol), the number and percentage of patients within each category (according to the scale used) is displayed. For changes in PF-10 score, summary statistics (mean, standard deviation, minimum, median, maximum) are provided. For all efficacy measures, results were also analyzed in several patient subgroups (ie, GOLD ABCD groups based on mMRC dyspnea scale and history of COPD exacerbations, ${ }^{31}$ maintenance therapy-naïve patients versus those previously treated, and baseline use of ICS vs no use of ICS). Patients were also stratified by number of exacerbations experienced in the previous 12 months (infrequent $[\leq 1$ exacerbation] and frequent [ $\geq 2$ exacerbations]).

For subgroups, PGE and patient satisfaction were compared by Chi-squared test. If the Chi-squared test was not valid, Fisher's exact test was used, or the PGE and patient satisfaction were treated as continuous outcomes and then compared by Wilcoxon rank-sum test (Mann-Whitney $U$-test) or Kruskal-Wallis test. For subgroups, changes from baseline in PF-10 were compared by Wilcoxon rank-sum test
(Mann-Whitney $U$-test) or Kruskal-Wallis test. For change from baseline in PF-10, 95\% CIs were calculated. P-values $\leq 0.05$ were considered statistically significant and are to be interpreted nominally.

\section{Results}

\section{Patient Characteristics}

Overall, 7477 patients were screened, of which 7443 were included in the TS and 7218 in the FAS (Figure 1). Patients in the TS had a mean age of 65.1 years, $68.4 \%$ were male and 41.4\% were current smokers. Based on GOLD 2017, 48.9\% were classified GOLD B, 24.2\% GOLD D, 21.8\% GOLD A and 5.1\% GOLD C (Table 1). Over two-thirds of patients (72.1\%) had recorded comorbidities (Tables 1 and 2).

At baseline, mMRC scores revealed that patients were predominantly suffering from grade $2(42.4 \%)$ and grade 3 (25.2\%) dyspnea severity (Table 1 ), had a mean PF-10 score of $46.1 \pm 23.3$ (Table 3), and a PGE score of predominantly $3(26.4 \%)$ or $4(29.9 \%)$, corresponding to a satisfactory general condition (Figure 2). A total of 2384 patients $(32.0 \%)$ were treatment naïve (no COPD

$\mathbf{7 4 7 7}$ patients screened

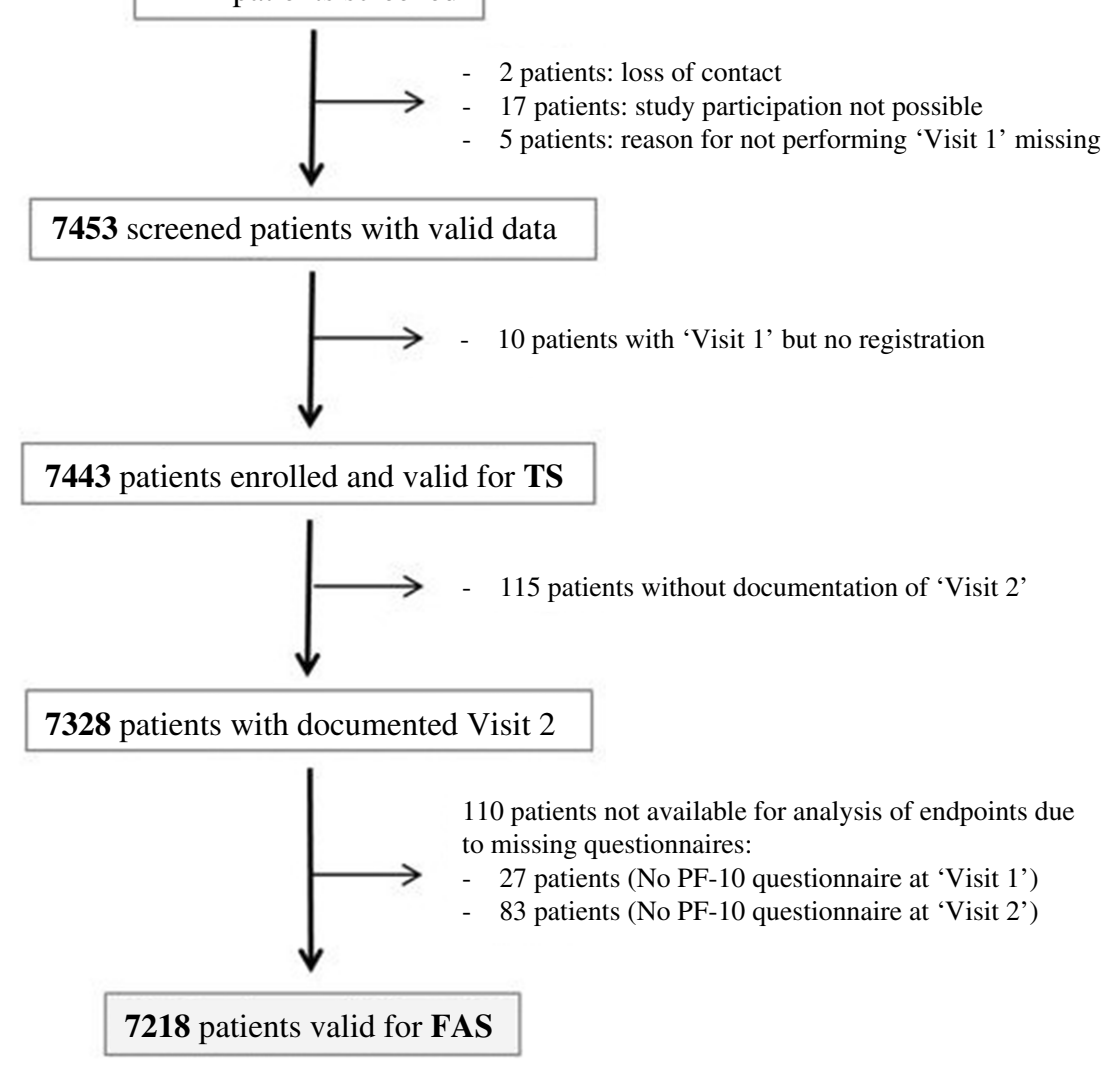

Figure I Patient flow chart.

Abbreviations: FAS, full analysis set; PF-10, 10-question Physical Functioning Questionnaire; TS, treated set. 
Table I Demographic And Baseline Data Of Patients In The Treated Set $(\mathrm{N}=7443)$

\begin{tabular}{|c|c|}
\hline Variable & \\
\hline Age at registration & \\
\hline Mean, years (SD) & $65.1(9.3)$ \\
\hline$\leq 65$ years, $n(\%)$ & $3783(50.8)$ \\
\hline$>65-<75$ years, $n(\%)$ & $2438(32.8)$ \\
\hline$\geq 75$ years, $\mathrm{n}(\%)$ & $1222(16.4)$ \\
\hline Sex & \\
\hline Male, n (\%) & $5094(68.4)$ \\
\hline Patients with concomitant diseases & \\
\hline$n(\%)$ & $5366(72.1)$ \\
\hline $\begin{array}{l}\text { Patients taking concomitant medication } \\
\text { (except respiratory therapeutics) }\end{array}$ & \\
\hline n (\%) & $4482(60.2)$ \\
\hline Smoking status & \\
\hline Smoker, n (\%) & $3080(41.4)$ \\
\hline Ex-smoker, n (\%) & $3325(44.7)$ \\
\hline Never smoked, n (\%) & $1038(14.0)$ \\
\hline Pack-years & \\
\hline Mean (SD) & $35.1(19.8)$ \\
\hline $\begin{array}{l}\text { Duration between initial diagnosis and baseline } \\
\text { visit }\end{array}$ & \\
\hline Years, mean (SD) & $4.8(5.86)$ \\
\hline COPD degree of severity, spirometric & \\
\hline Patients in stage GOLD I, n (\%) & $119(1.60)$ \\
\hline Patients in stage GOLD 2, n (\%) & $3379(45.40)$ \\
\hline Patients in stage GOLD 3, n (\%) & $3111(41.80)$ \\
\hline Patients in stage GOLD 4, n (\%) & $744(10.00)$ \\
\hline mMRC Questionnaire & \\
\hline Patients with grade $0, \mathrm{n}(\%)$ & $238(3.2)$ \\
\hline Patients with grade I, n (\%) & $1763(23.7)$ \\
\hline Patients with grade $2, \mathrm{n}(\%)$ & $3157(42.4)$ \\
\hline Patients with grade $3, \mathrm{n}(\%)$ & $1874(25.2)$ \\
\hline Patients with grade $4, \mathrm{n}(\%)$ & $411(5.5)$ \\
\hline $\begin{array}{l}\text { GOLD group, based on symptoms and } \\
\text { exacerbations only (version 20I7) }\end{array}$ & \\
\hline Patients in group $A, n(\%)$ & $1625(21.8)$ \\
\hline Patients in group $\mathrm{B}, \mathrm{n}(\%)$ & 3639 (48.9) \\
\hline Patients in group C, $\mathrm{n}(\%)$ & $376(5.1)$ \\
\hline Patients in group $D, n(\%)$ & $1803(24.2)$ \\
\hline Exacerbations in the 12 months prior to the study & \\
\hline Number of exacerbations & 8014 \\
\hline Patients with at least one event, $n(\%)$ & $4831(64.9)$ \\
\hline Mean (SD) & I.I (I.I) \\
\hline
\end{tabular}

treatment within the 6 months prior to study treatment). Of the $68 \%$ of patients who were treated with respiratory
Table 2 Concomitant Diseases And Medication Use At Baseline In The Treated Set

\begin{tabular}{|l|l|}
\hline Concomitant diseases & $\begin{array}{l}\text { Number (\%) of } \\
\text { patients }^{\mathbf{a}}\end{array}$ \\
\hline Allergic disease & $153(2.1)$ \\
Cardiac & $3162(42.5)$ \\
Gastrointestinal/hepatobiliary & $914(12.3)$ \\
Metabolic/endocrine & $1799(24.2)$ \\
Musculoskeletal/dermatologic & $488(6.6)$ \\
Neurologic & $307(4.1)$ \\
Pulmonary (except COPD) & $439(5.9)$ \\
Psychiatric & $274(3.7)$ \\
Renal/urogenital & $367(4.9)$ \\
Vascular & $2174(29.2)$ \\
Other & $424(5.7)$ \\
\hline COPD therapies taken 6 months prior & \\
to study start & \\
\hline ICS monotherapy & $326(4.4)$ \\
LABA & $1100(14.8)$ \\
LAMA & $1999(26.9)$ \\
SABA & $1056(14.2)$ \\
SAMA & $513(6.9)$ \\
SAMA+SABA in fixed-dose combination & $1071(14.4)$ \\
LABA+ICS & $859(11.5)$ \\
LAMA+LABA in fixed-dose combination & $50(0.7)$ \\
Systemic corticosteroid & $45(0.6)$ \\
Theophylline & $719(9.7)$ \\
Roflumilast & $36(0.5)$ \\
Other & $192(2.6)$ \\
\hline
\end{tabular}

Notes: a“Multiple answers possible", meaning that patients might have more than one concomitant disease.

Abbreviations: ICS, inhaled corticosteroid; LABA, long-acting $\beta_{2}$-agonist; LAMA, long-acting muscarinic antagonist; SABA, short-acting $\beta_{2}$-agonist; SAMA, short-acting muscarinic antagonist.

therapeutics, $26.9 \%$ received LAMAs, $14.8 \%$ received LABAs, $14.2 \%$ received short-acting $\beta_{2}$-agonists, and $11.5 \%$ of the patients were pre-treated with LABA+ICS (Table 2).

\section{Physical Functioning}

Therapeutic success was achieved in 67.8\% (95\% CI: 66.7, 68.8) of patients (FAS) (Table 3). A mean improvement in PF10 score from baseline of 16.6 points was observed (95\% CI: $16.2,17.0)$. The highest therapeutic success rates were observed in GOLD D $(79.7 \%$; 95\% CI: $77.7,81.6)$ and GOLD B patients $(70.9 \%$; 95\% CI: 69.4, 72.4) followed by GOLD C (58.5\%; 95\% CI: 5302, 63.7) and GOLD A (49.3\%; 95\% CI: 46.8, 51.8) $(\mathrm{P}<0.0001)$ (Table 3). This difference by GOLD group is also highlighted when assessed by absolute change in PF-10 score (Supplementary Figure 1). Similarly, 
Table 3 Ten-question Physical Functioning Questionnaire Scores At Visits I And 2, And Change From Baseline (full Analysis Set) ( $N=72$ I8)

\begin{tabular}{|c|c|}
\hline \multicolumn{2}{|l|}{ PF-IO score } \\
\hline Visit I (baseline) & \\
\hline Mean (SD) & $46.1(23.3)$ \\
\hline Median (min-max) & $45.0(0-100)$ \\
\hline $95 \% \mathrm{Cl}$ & $45.6,46.7$ \\
\hline \multicolumn{2}{|c|}{ Visit 2 (after approximately 6 weeks) } \\
\hline Mean (SD) & $62.7(21.5)$ \\
\hline Median (min-max) & $65.0(0-100)$ \\
\hline $95 \% \mathrm{Cl}$ & $62.2,63.2$ \\
\hline \multicolumn{2}{|c|}{$\begin{array}{l}\text { Therapeutic success (proportion of patients with a } \geq 10 \text {-point } \\
\text { increase in PF-10 after approx. } 6 \text { weeks) }\end{array}$} \\
\hline \multicolumn{2}{|l|}{ Overall } \\
\hline n (\%) & $4891(67.8)$ \\
\hline $95 \% \mathrm{Cl}$ & $66.7,68.8$ \\
\hline \multicolumn{2}{|l|}{ GOLD A ${ }^{a}$} \\
\hline n (\%) & $766(49.3)$ \\
\hline $95 \% \mathrm{Cl}$ & $46.8,51.8$ \\
\hline \multicolumn{2}{|l|}{ GOLD Ba } \\
\hline n (\%) & $2515(70.9)$ \\
\hline $95 \% \mathrm{Cl}$ & $69.4,72.4$ \\
\hline \multicolumn{2}{|l|}{ GOLD C ${ }^{a}$} \\
\hline n (\%) & $209(58.5)$ \\
\hline $95 \% \mathrm{Cl}$ & $53.2,63.7$ \\
\hline \multicolumn{2}{|l|}{ GOLD D ${ }^{\mathrm{a}}$} \\
\hline n (\%) & $|40|(79.7)$ \\
\hline $95 \% \mathrm{Cl}$ & $77.7,81.6$ \\
\hline
\end{tabular}

Notes: ${ }^{a}$ GOLD subgroup according to 2017 classification, based on symptoms and exacerbations only.

Abbreviation: PF-10, 10-question Physical Functioning Questionnaire. there was a statistically significant difference in therapeutic success rates between patients with mild and moderate airflow obstruction when compared with patients with more severe airflow obstruction (64\% therapeutic success rate for GOLD 1 and 2 vs $70.9 \%$ therapeutic success rate for GOLD 3 and 4) $(\mathrm{P}<0.0001)$ (Supplementary Table 1). A higher proportion of patients with frequent $(\geq 2)$ exacerbations reported therapeutic success, compared with patients with infrequent exacerbations, $76.1 \%$ (95\% CI: $74.3,77.9)$ vs $64.3 \%$ (95\% CI: 63.0 , $65.6)$, respectively $(\mathrm{P}<0.0001)$. There was no significant difference $(\mathrm{P}=0.4534)$ in the proportion of patients with therapeutic success between maintenance-naïve $(68.0 \%$; $95 \%$ CI: $66.74,69.24)$ and pre-treated (67.1\%; 95\% CI: 64.84, 69.21) patients. This was also true for patients who received previous therapy with ICS at baseline (66.9\%; 95\% CI: 64.0, 69.7) compared with those with no prior ICS therapy $(67.9 \%$; $95 \%$ CI: 66.7, 69.1) $(\mathrm{P}=0.5127)$.

\section{Patient General Condition And Self-Reported Treatment Satisfaction}

A shift towards an improvement in patient general condition was seen from baseline (11.8\% scored PGE 1-2 corresponding to "poor" condition, $56.3 \%$ scored PGE 3-4, corresponding to "satisfactory" condition; $31.9 \%$ scored PGE 5-8, corresponding to "good/excellent" condition) to study end (0.7\% scored $1-2,16.0 \%$ scored $3-4,83.3 \%$ scored 5-8) (post hoc grouping and analysis, $\mathrm{P}<0.0001$ ) (Figure 2). Eighty-one percent of patients were satisfied/very satisfied with tiotropium/olodaterol treatment overall, $85 \%$ with inhaling from the soft mist inhaler device and $84 \%$ with device

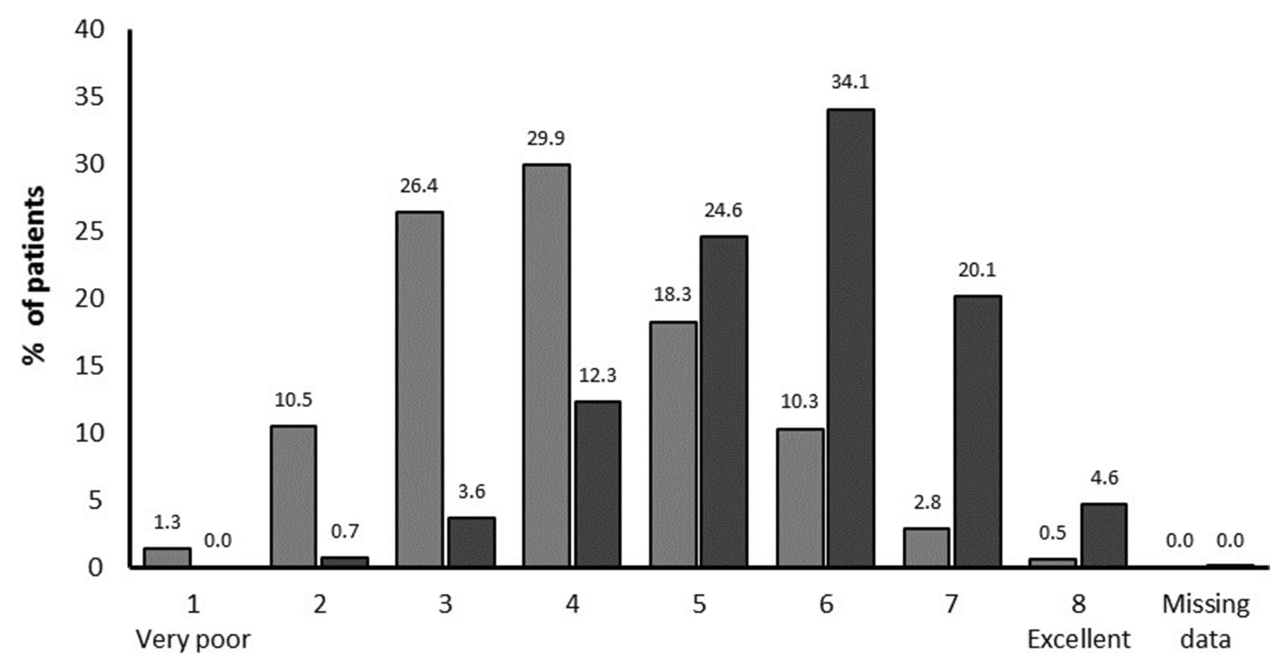

$\square$ Visit 1 Visit 2

Figure 2 General patient condition: Physician's Global Evaluation score. 


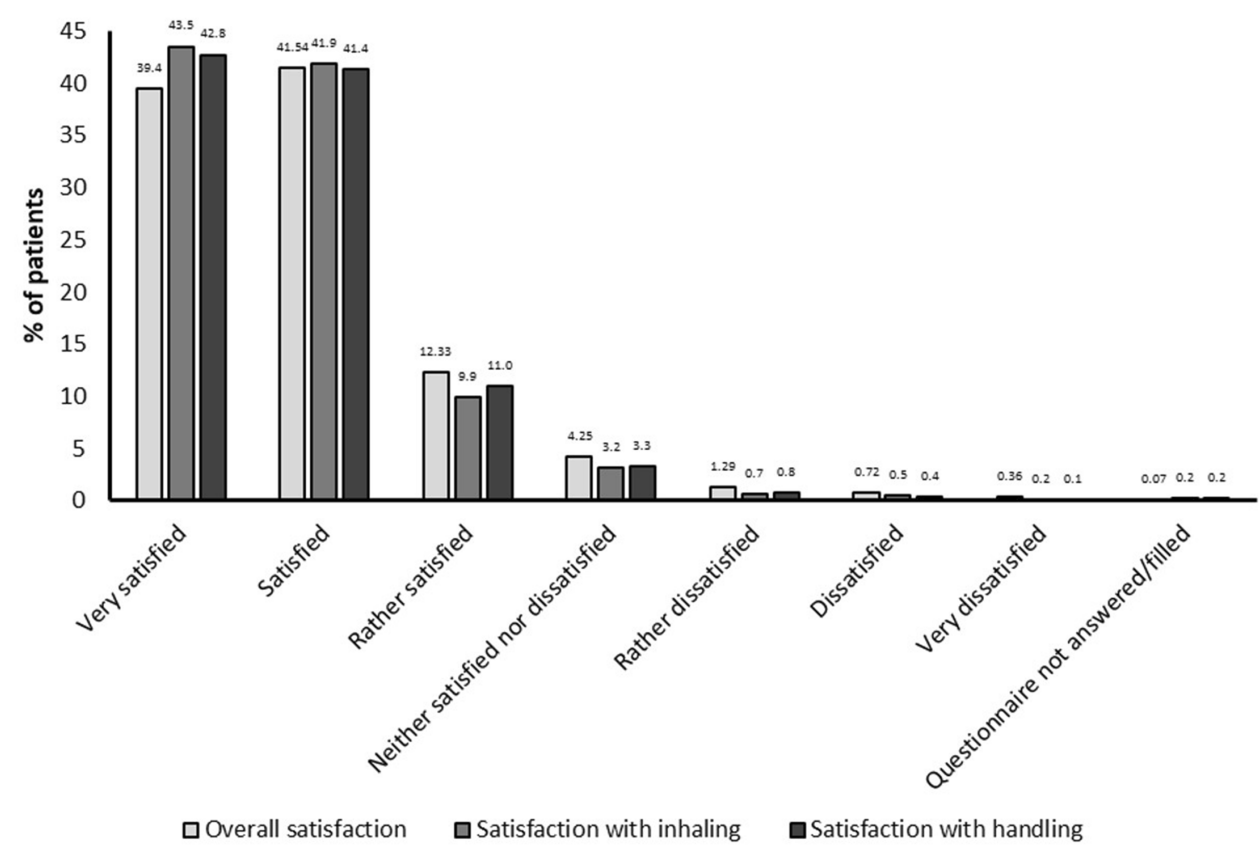

Figure 3 Patient overall satisfaction with treatment.

handling (Figure 3). Patient satisfaction was also reflected by a high proportion of patients continuing tiotropium/olodaterol treatment at the end of the observational period (95\%).

\section{Safety}

Overall, 110 drug-related AEs were reported by $1.3 \%$ (96/7443) of the TS population. The most common drug-related AEs included cough (30 events), dry mouth (23 events), and COPD worsening (exacerbations; 10 events). Forty-seven patients discontinued treatment, predominantly due to cough (10 patients), worsening of COPD (exacerbations; 9 patients) and dry mouth (8 patients). A total of five serious AEs (atrial fibrillation, pneumonia, sepsis, neoplasm, and neoplasm progression), including one serious drugrelated AE (atrial fibrillation) (Table 4), were documented in five patients, four of which were fatal and one required hospitalization.

Table 4 Summary Of Drug-related Adverse Events In The Treated Set $(\mathrm{N}=7443)$

\begin{tabular}{|l|l|}
\hline AE category & Number (\%) of patients \\
\hline All AEs & $96(1.3)$ \\
Serious AEs & $5(0.07)$ \\
AEs leading to discontinuation & $47(0.63)$ \\
Fatal AEs & $4(0.05)$ \\
\hline
\end{tabular}

Abbreviation: $\mathrm{AE}$, adverse event

\section{Discussion}

This observational study investigated the effect of tiotropium/olodaterol FDC on self-reported physical functioning in a large population of patients with a wide range of COPD severity in Central and Eastern Europe. The majority of patients in this study reported clinically meaningful improvements in physical functioning, as measured by an increase in PF-10 score of at least 10 points, in response to dual bronchodilator therapy. We did not observe a statistically significant difference in the proportion of patients with therapeutic success between pre-treated and maintenance-naïve groups, or between patients with or without ICS use. Patients were also found to be in better general condition after the treatment period and reported a high rate of overall treatment and inhaler device satisfaction.

Physical activity is an independent predictor of healthrelated quality of life, ${ }^{32}$ hospital admissions, ${ }^{9}$ as well as allcause and disease-specific morbidity and mortality. ${ }^{33}$ Inhaled bronchodilator therapy may exert a positive impact on physical activity on the basis of a variety of mechanisms, such as improvements in breathlessness, ${ }^{34}$ static and dynamic hyperinflation, ${ }^{35,36}$ breathing effort,,${ }^{17,37}$ cardiovascular function, ${ }^{38}$ and/or exercise capacity. ${ }^{15,20,39}$

Data from randomized controlled clinical trials have shown an increase in exercise endurance with dual bronchodilator therapy compared with monotherapy. ${ }^{15}$ Nevertheless, it is still not clear whether the observed 
effects on exercise capacity translate to true changes in daily physical activity in patients. ${ }^{40,41}$

Physical activity is affected by many factors including patient behavior. ${ }^{20}$ Although bronchodilation treatment in patients with COPD has been found to increase exercise tolerance, ${ }^{42}$ this does not always translate to a more active lifestyle in patients. This may be due to negative patient experiences during physical activity or a lack of motivational and behavioral factors in pulmonary rehabilitation programs. ${ }^{43}$ Previous studies have demonstrated that there are significant differences in the perception of how COPD affects daily activities in patients and the understanding that physicians have of their patients' perception. ${ }^{44,45}$ In order to prescribe the optimal treatment strategy to improve symptoms and quality of life, awareness of the impact of patient perception is essential. The current study reinforces this theory using self-reported questionnaires and demonstrates that a large proportion of the trial population felt improvements in their ability to carry out daily activities resulted in high patient satisfaction with the treatment.

Furthermore, assessment of self-reported physical activity may serve as an important alternative to objective assessments of physical activity. ${ }^{32}$ Physical activity and physical capacity are integral components of patient-reported outcome assessments, such as the St. George's Respiratory Questionnaire (SGRQ), one of the most frequently used health-related quality of life tools in clinical trials in COPD. Previous studies using either free-dose or FDCs of tiotropium and olodaterol delivered via soft mist inhaler device demonstrated improved SGRQ scores in patients with moderate to severe COPD when compared with mono-components. $^{34,46}$ The SGRQ, however, is of limited use in day-to-day clinical practice. In contrast, the PF-10 can be easily completed within few minutes in a physicians' office. $^{47}$ It is a validated subdomain of the SF-36 score, designed to examine a person's perceived limitation with physical functioning, in which subjects are asked if their condition limits not only physical activity, but also basic mobility, and basic activities of daily living. ${ }^{27}$ Self-reported functional limitations are common in COPD among persons with a broad range of disease severity, and accompanied by muscle weakness and impaired exercise tolerance. ${ }^{48}$

Our data corroborate two previous observational studies using the PF-10 in patients with COPD and comparable disease characteristics. ${ }^{22,30}$ Both studies, conducted by German pulmonologists, reported improvements in PF-10 score after 6 weeks of tiotropium mono or tiotropium/olodaterol free-dose combination therapy, respectively. ${ }^{22,30}$ The magnitude of PF-10 score improvement (16.6 points) and the proportion of patients categorized to be in good or excellent general condition in the present study may suggest a higher treatment response to tiotropium/olodaterol FDC than reported in previous studies with monotherapy or freedose combination therapy of the bronchodilators, with a 13.4 points and 10.2 points $\mathrm{PF}-10$ score treatment difference at 6 weeks, respectively. ${ }^{22,30}$ Importantly, the overall safety profile in these studies was similar. ${ }^{29}$

In contrast to the above reports we had a relatively high proportion of GOLD A patients who received tiotropium/ olodaterol FDC from their treating physicians, a therapeutic approach currently not recommended by treatment strategy. ${ }^{14}$ This may, in part, be explained by the method used to categorize patients into the GOLD risk groups. In fact, mMRC- and CAT-based approaches to estimate symptoms have provided contradictory results and can result in underestimation of patient severity by physicians. ${ }^{49,50}$ Thus, it may be possible that a proportion of our patients would indeed qualify for GOLD B, if CAT were used. In that case, the use of LAMA/LABA treatment would be considered consistent with the GOLD treatment recommendations, in patients with a high symptom load. On the other hand, our findings may confirm previous studies showing discordance in inhaler COPD management between treatment recommendations and clinical practice, on both a primary and secondary care level. ${ }^{51}$ Factors responsible for this phenomenon may include lack of awareness of recommendations, ${ }^{51}$ difficulties in distinguishing between asthma and COPD in clinical practice, ${ }^{52}$ and/or reimbursement-related factors. ${ }^{53}$ There may also be a shift towards early intervention with LAMA/LABA FDC in COPD in clinical practice, based on the cumulating scientific evidence of their ability to improve lung function and measures of disease worsening, when compared with mono-bronchodilator or LABA/ICS therapy. ${ }^{54-57}$ In this context, further studies are required to investigate physician treatment behavior in real-life clinical studies.

Furthermore, we observed a higher PF-10 responder rate in frequent exacerbators ( $\geq 2$ exacerbations in 12 months) compared with infrequent exacerbators $(\leq 1$ in 12 months). This is of particular importance, as both moderate $^{58}$ and severe exacerbations ${ }^{59}$ have been shown to impact physical activity. Improvements in physical functioning and general condition through dual bronchodilation, as seen in this study, could encourage patients to adopt a more active lifestyle, resulting in an improved 
quality of life and lower risk of COPD-related hospitalizations. ${ }^{60,61}$ Additionally, there is evidence of a direct impact of dual bronchodilator therapy on exacerbation rates in COPD. ${ }^{62-65}$

We should acknowledge a number of limitations in this study. First and foremost, the current study is a real-world observational study and not a randomized controlled clinical trial lacking a control group with which to compare the intervention. The differential treatment response observed in patients with differing disease stage, however, may suggest a true therapeutic intervention rather than a mere placebo effect. Second, we used a questionnaire to establish the level of physical activity rather than a direct measure. While questionnaires on physical activity only have a moderate level of concordance with objective assessments of physical activity, they have a tendency towards overestimation rather than underestimation compared with objective methods. ${ }^{66,67}$ While the threshold of 10 points for clinically relevant changes in the PF-10 has been selected on the basis of statistical rationale, we need to acknowledge that this cut-off has not been validated in terms of its clinical impact beyond daily physical activity or its correlation with other patient-reported outcomes. Similarly, we did not perform lung function measurements during follow-up to correlate any potential improvements in airway physiology with the benefits observed in physical activity. Despite these limitations, self-reported levels of physical activity, such as time patients spent walking during their leisure time, have been reported as important independent predictors of health-related quality of life in COPD. ${ }^{32}$ Third, we must acknowledge the rather short duration of the observational period. As this study relied on patient self-reported data there was a risk of recall bias, which could affect the validity of the data collected, the shorter study duration was the best approach to minimize this risk. ${ }^{25}$ Participants can inaccurately recall a past event, which can influence their responses. Should this effect be underestimated, the true effect or association of the treatment could be incorrectly recorded. Recall bias has been associated with multiple factors, including the length of recall period. ${ }^{26}$ Previous studies have demonstrated that short recall periods are better than longer periods, especially when asking patients to recall routine or frequent events. ${ }^{25,26}$ Further studies to evaluate alignment between gold-standard data collection sources and self-reported methods are needed to clearly define appropriate timelines to reduce the risk of such bias. Finally, patient use of concomitant medications and patient adherence to the treatment regimen was self-controlled and there was no treatment diary; patient use and adherence to tiotropium/ olodaterol was therefore dependent on physician inquiry and could not be verified or controlled. As such, the effect these variables may have had on efficacy and safety is unknown.

Strengths of this non-interventional study include a large, international patient population, with varying disease severity and a spectrum of comorbidities, treated for COPD in clinical practice, allowing these data to be more readily generalized to a real-life setting. ${ }^{68}$ Thus, the efficacy and safety data observed here complement findings from previous randomized controlled clinical trials of LAMA/LABA FDC therapy in patients with COPD.

\section{Conclusion}

Treatment with tiotropium/olodaterol via soft mist inhaler device under real-life conditions led to an improvement in self-reported physical functioning and PGE scores, as well as in patient satisfaction with treatment via the inhaler device across a wide range of COPD severities.

\section{Abbreviations}

AE, adverse event; FAS, full analysis set; FDC, fixed-dose combination; ICS, inhaled corticosteroid; LABA, long-acting $\beta_{2}$-agonist; LAMA, long-acting muscarinic antagonist; PF-10, 10-question Physical Functioning Questionnaire; PGE, Physician's Global Evaluation; SF-36, 36-item Short Form Health Survey; SGRQ, St. George's Respiratory Questionnaire; TS, treated set.

\section{Acknowledgments}

This work was supported by Boehringer Ingelheim International GmbH. Medical writing assistance was provided by Martina Stagno d'Alcontres, PhD, CMPP of MediTech Media Ltd., who was contracted and compensated by Boehringer Ingelheim International $\mathrm{GmbH}$. The abstract of this paper was presented at the ERS International Congress, Paris 2018 as a poster presentation with interim findings. The poster's abstract was published in "Poster Abstracts" in European Respiratory Journal: https://erj.ersjournals.com/content/52/suppl_62/PA912.

\section{Author contributions}

The authors meet criteria for authorship as recommended by the International Committee of Medical Journal Editors. They take full responsibility for the scope, direction, content of, and editorial decisions relating to, the manuscript, were 
involved at all stages of development, and have approved the submitted manuscript. All authors contributed to data analysis, drafting and revising the article, gave final approval of the version to be published, and agree to be accountable for all aspects of the work.

\section{Disclosure}

Dr Arschang Valipour reports personal fees, non-financial support from Boehringer Ingelheim, personal fees from Novartis, Chiesi, and AstraZeneca, during the conduct of the study. Dr Valentina Bayer, Dr Maria Sanzharovskaya, Dr Alexey Medvedchikov are employees of Boehringer Ingelheim. Prof. Dr Zvi Fridlender reports personal fees and institutional support from Boehringer Ingelheim, during the conduct of the study. Prof Dr. Zvi Fridlender also reports personal fees from GSK, Novartis, AstraZeneca, Boehringer Ingelheim, Teva, and Rafa, outside the submitted work. Dr Claudia Toma reports grants, personal fees from Boehringer Ingelheim, during the conduct of the study, personal fees, non-financial support from AstraZeneca, Berlin Chemie, Boehringer Ingelheim, Novartis, Roche, Sandoz and Chiesi, personal fees from Amring, Bayer Pharma, Cipla, and Bristol Myers Squibb, and non-financial support from Actelion, Angelini, and Terapia, from outside the submitted work. The authors report no other conflicts of interest in this work.

\section{References}

1. World Health Organization. Chronic obstructive pulmonary disease (COPD). Available from: http://www.who.int/mediacentre/factsheets/ fs315/en/. Accessed February 19, 2018.

2. Rabe KF, Watz H. Chronic obstructive pulmonary disease. Lancet. 2017;389(10082):1931-1940. doi:10.1016/S0140-6736(17)31222-9

3. Bidan CM, Veldsink AC, Meurs H, Gosens R. Airway and extracellular matrix mechanics in COPD. Front Physiol. 2015;6:346. doi:10.3389/fphys.2015.00346

4. Casaburi R. Activity promotion: a paradigm shift for chronic obstructive pulmonary disease therapeutics. Proc Am Thorac Soc. 2011;8 (4):334-337. doi:10.1513/pats.201101-001RM

5. Corbridge SJ, Nyenhuis SM. Promoting physical activity and exercise in patients with asthma and chronic obstructive pulmonary disease. $J$ Nurse Pract. 2017;13(1):41-46. doi:10.1016/j.nurpra.2016.08.022

6. Troosters T, Sciurba F, Battaglia S, et al. Physical inactivity in patients with COPD, a controlled multi-center pilot-study. Respir Med. 2010;104(7):1005-1011. doi:10.1016/j.rmed.2010.01.012

7. Watz H, Waschki B, Meyer T, Magnussen H. Physical activity in patients with COPD. Eur Respir J. 2009;33(2):262-272. doi:10.1183/ 09031936.00024608

8. Gea J, Pascual S, Casadevall C, Orozco-Levi M, Barreiro E. Muscle dysfunction in chronic obstructive pulmonary disease: update on causes and biological findings. J Thorac Dis. 2015;7(10):E418-E438.

9. Pitta F, Troosters T, Probst VS, Spruit MA, Decramer M, Gosselink R. Quantifying physical activity in daily life with questionnaires and motion sensors in COPD. Eur Respir J. 2006;27(5):1040-1055. doi:10.1183/09031936.06.00064105
10. Ding B, Small M, Bergstrom G, Holmgren U. COPD symptom burden: impact on health care resource utilization, and work and activity impairment. Int $J$ Chron Obstruct Pulmon Dis. 2017;12:677-689. doi:10.2147/COPD.S123896

11. Laurin C, Moullec G, Bacon SL, Lavoie KL. Impact of anxiety and depression on chronic obstructive pulmonary disease exacerbation risk. Am J Respir Crit Care Med. 2012;185(9):918-923. doi:10.11 64/rccm.201105-0939PP

12. Giardino ND, Curtis JL, Andrei AC, et al. Anxiety is associated with diminished exercise performance and quality of life in severe emphysema: a cross-sectional study. Respir Res. 2010;11:29. doi:10.1186/ 1465-9921-11-29

13. Pitta F, Troosters T, Spruit MA, Probst VS, Decramer M, Gosselink R. Characteristics of physical activities in daily life in chronic obstructive pulmonary disease. Am J Respir Crit Care Med. 2005;171(9):972-977. doi:10.1164/rccm.200407-855OC

14. Global Initiative for Chronic Obstructive Lung Disease. Global strategy for the diagnosis, management, and prevention of chronic obstructive pulmonary disease: 2018 report. Available from: https:// goldcopd.org/gold-reports/. Accessed July 17, 2018.

15. O'Donnell DE, Casaburi R, Frith P, et al. Effects of combined tiotropium/olodaterol on inspiratory capacity and exercise endurance in COPD. Eur Respir J. 2017;49(4):1601348. doi:10.1183/139930 03.01348-2016

16. Thomas M, Decramer M, O'Donnell DE. No room to breathe: the importance of lung hyperinflation in COPD. Prim Care Respir J. 2013;22(1):101-111. doi:10.4104/pcrj.2013.00025

17. O’Donnell DE, Fluge T, Gerken F, et al. Effects of tiotropium on lung hyperinflation, dyspnoea and exercise tolerance in COPD. Eur Respir J. 2004;23(6):832-840. doi:10.1183/09031936.04.00116004

18. O'Donnell DE. Hyperinflation, dyspnea, and exercise intolerance in chronic obstructive pulmonary disease. Proc Am Thorac Soc. 2006;3 (2):180-184. doi:10.1513/pats.200508-093DO

19. Maltais F, O'Donnell D, Galdiz Iturri JB, et al. Effect of 12 weeks of once-daily tiotropium/olodaterol on exercise endurance during constant work-rate cycling and endurance shuttle walking in chronic obstructive pulmonary disease. Ther Adv Respir Dis. 2018;12:1-13. doi: $10.1177 / 1753465818755091$

20. Troosters T, Maltais F, Leidy N, et al. Effect of bronchodilation, exercise training, and behavior modification on symptoms and physical activity in chronic obstructive pulmonary disease. Am J Respir Crit Care Med. 2018;198(8):1021-1032. doi:10.1164/rccm.201706$1288 \mathrm{OC}$

21. Peeters G, Dobson A, Deeg D, Brown W. A life-course perspective on physical functioning in women. Bull World Health Organ. 2013;91(9):661-670. doi:10.2471/BLT.13.123075

22. Sauer R, Hansel M, Buhl R, Rubin RA, Frey M, Glaab T. Impact of tiotropium + olodaterol on physical functioning in COPD: results of an open-label observational study. Int J Chron Obstruct Pulmon Dis. 2016;11:891-898.

23. Steinmetz K, Abenhardt B, Pabst S, et al. Physical functioning, general condition and satisfaction with tiotropium/olodaterol in realworld COPD patients in Germany. Abstract submitted to European Respiratory Society International Congress; 2018; Paris.

24. Boehringer Ingelheim Limited. Spiolto Respimat 2.5 microgram/2.5 microgram, inhalation solution - summary of product characteristics. Available from: https://www.medicines.org.uk/emc/medicine/30495. Accessed February 28, 2018.

25. Hassan E. Recall bias can be a threat to retrospective and prospective research designs. Internet J Epidemiol. 2018;3(2):4.

26. Althubaiti A. Information bias in health research: definition, pitfalls, and adjustment methods. J Multidiscip Healthc. 2016;9:211-217. doi:10.2147/JMDH.S104807

27. Ware JE Jr, Sherbourne CD. The MOS 36-item short-form health survey (SF-36). I. Conceptual framework and item selection. Med Care. 1992;30(6):473-483. doi:10.1097/00005650-199206000-00002 
28. Cohen J, editor. Statistical Power Analysis for the Behavioral Sciences. 1st ed. Hillsdale (NJ): Lawrence Erlbaum Associates Inc.; 1977.

29. Steinmetz K, Abenhardt B, Pabst S, et al. Assessment of physical functioning and handling of tiotropium/olodaterol Respimat ${ }^{\mathbb{B}}$ in patients with COPD in a real-world clinical setting. Int $J$ Chron Obstruct Pulmon Dis. 2019;14:1441-453. doi:10.2147/COPD. $\mathrm{S} 195852$

30. Rau-Berger H, Mitfessel H, Glaab T. Tiotropium Respimat ${ }^{\circledR}$ improves physical functioning in chronic obstructive pulmonary disease. Int J Chron Obstruct Pulmon Dis. 2010;5:367-373. doi:10.21 47/COPD.S14082

31. Global Initiative for Chronic Obstructive Lung Disease. GOLD 2017: global strategy for the diagnosis, management and prevention of COPD - Global Initiative for Chronic Obstructive Lung Disease (GOLD). Available from: http://goldcopd.org/gold-2017-global-strat egy-diagnosis-management-prevention-copd/. Accessed September 6, 2017.

32. Esteban C, Quintana JM, Aburto M, et al. Impact of changes in physical activity on health-related quality of life among patients with COPD. Eur Respir J. 2010;36(2):292-300. doi:10.1183/0903 1936.00021409

33. Waschki B, Kirsten A, Holz O, et al. Physical activity is the strongest predictor of all-cause mortality in patients with COPD: a prospective cohort study. Chest. 2011;140(2):331-342. doi:10.1378/ chest.10-2521

34. Buhl R, Maltais F, Abrahams R, et al. Tiotropium and olodaterol fixed-dose combination versus mono-components in COPD (GOLD 2-4). Eur Respir J. 2015;45(4):969-979. doi:10.1183/09031936.001 36014

35. Beeh KM, Westerman J, Kirsten AM, et al. The 24-h lung-function profile of once-daily tiotropium and olodaterol fixed-dose combination in chronic obstructive pulmonary disease. Pulm Pharmacol Ther. 2015;32:53-59. doi:10.1016/j.pupt.2015.04.002

36. O'Donnell DE, Lam M, Webb KA. Measurement of symptoms, lung hyperinflation, and endurance during exercise in chronic obstructive pulmonary disease. Am J Respir Crit Care Med. 1998;158(5):15571565. doi:10.1164/ajrccm.158.5.9804004

37. O'Donnell DE, Hamilton AL, Webb KA. Sensory-mechanical relationships during high-intensity, constant-work-rate exercise in COPD. J Appl Physiol. 2006;101(4):1025-1035. doi:10.1152/ japplphysiol.01470.2005

38. Hohlfeld JM, Vogel-Claussen J, Biller H, et al. Effect of lung deflation with indacaterol plus glycopyrronium on ventricular filling in patients with hyperinflation and COPD (CLAIM): a double-blind, randomised, crossover, placebo-controlled, single-centre trial. Lancet Respir Med. 2018;6(5):368-378. doi:10.1016/S2213-2600 (18)30054-7

39. Ichinose M, Minakata Y, Motegi T, et al. Efficacy of tiotropium/ olodaterol on lung volume, exercise capacity, and physical activity. Int J Chron Obstruct Pulmon Dis. 2018;13:1407-1419. doi:10.2147/ COPD.S166023

40. Zwerink M, van der Palen J, van der Valk P, Brusse-Keizer M, Effing T. Relationship between daily physical activity and exercise capacity in patients with COPD. Respir Med. 2013;107(2):242-248. doi:10.10 16/j.rmed.2012.09.018

41. Shioya T, Sato S, Iwakura M, et al. Improvement of physical activity in chronic obstructive pulmonary disease by pulmonary rehabilitation and pharmacological treatment. Respir Investig. 2018;56(4):292-306. doi:10.1016/j.resinv.2018.05.002

42. Borel B, Provencher S, Saey D, Maltais F. Responsiveness of various exercise-testing protocols to therapeutic interventions in COPD. Pulm Med. 2013;2013:410748. doi:10.1155/2013/410748

43. Bourbeau J, Lavoie KL, Sedeno M. Comprehensive self-management strategies. Semin Respir Crit Care Med. 2015;36(4):630-638. doi: $10.1055 / \mathrm{s}-00000075$
44. Celli B, Blasi F, Gaga M, et al. Perception of symptoms and quality of life - comparison of patients' and physicians' views in the COPD MIRROR study. Int J Chron Obstruct Pulmon Dis. 2017;12:21892196. doi:10.2147/COPD.S136711

45. Miravitlles M, Ribera A. Understanding the impact of symptoms on the burden of COPD. Respir Res. 2017;18(1):67. doi:10.1186/ s12931-017-0548-3

46. ZuWallack R, Allen L, Hernandez G, Ting N, Abrahams R. Efficacy and safety of combining olodaterol Respimat $\left({ }^{\circledR}\right)$ and tiotropium HandiHaler $\left({ }^{\circledR}\right)$ in patients with COPD: results of two randomized, double-blind, active-controlled studies. Int J Chron Obstruct Pulmon Dis. 2014;9:1133-1144. doi:10.2147/COPD.S72482

47. White DK, Wilson JC, Keysor JJ. Measures of adult general functional status: SF-36 Physical Functioning Subscale (PF-10), Health Assessment Questionnaire (HAQ), Modified Health Assessment Questionnaire (MHAQ), Katz Index of Independence in activities of daily living, Functional Independence Measure (FIM), and Osteoarthritis-Function-Computer Adaptive Test (OA-FunctionCAT). Arthritis Care Res. 2011;63 Suppl 11:S297-S307.

48. Eisner MD, Blanc PD, Yelin EH, et al. COPD as a systemic disease: impact on physical functional limitations. Am J Med. 2008;121 (9):789-796. doi:10.1016/j.amjmed.2008.04.030

49. Holt S, Sheahan D, Helm C, Tofield C, Corin A, Kocks JW. Little agreement in GOLD category using CAT and mMRC in 450 primary care COPD patients in New Zealand. NPJ Prim Care Respir Med. 2014;24:14025. doi:10.1038/npjpcrm.2014.25

50. Kim S, Oh J, Kim YI, et al. Differences in classification of COPD group using COPD assessment test (CAT) or modified Medical Research Council (mMRC) dyspnea scores: a cross-sectional analyses. BMC Pulm Med. 2013;13:35. doi:10.1186/1471-2466-13-35

51. Davis KJ, Landis SH, Oh YM, et al. Continuing to Confront COPD International Physician Survey: physician knowledge and application of COPD management guidelines in 12 countries. Int $J$ Chron Obstruct Pulmon Dis. 2014;10:39-55.

52. Miravitlles M, Andreu I, Romero Y, Sitjar S, Altes A, Anton E. Difficulties in differential diagnosis of COPD and asthma in primary care. Br J Gen Pract. 2012;62(595):e68-e75. doi:10.3399/bjgp12X62 5111

53. Bjornsdottir US, Sigurethardottir ST, Jonsson JS, et al. Impact of changes to reimbursement of fixed combinations of inhaled corticosteroids and long-acting beta(2) -agonists in obstructive lung diseases: a population-based, observational study. Int J Clin Pract. 2014;68 (7):812-819. doi:10.1111/ijcp.12473

54. Anzueto AR, Vogelmeier CF, Kostikas K, et al. The effect of indacaterol/glycopyrronium versus tiotropium or salmeterol/fluticasone on the prevention of clinically important deterioration in COPD. Int J Chron Obstruct Pulmon Dis. 2017;12:1325-1337. doi:10.2147/ COPD.S133307

55. Greulich T, Kostikas K, Gaga M, et al. Indacaterol/glycopyrronium reduces the risk of clinically important deterioration after direct switch from baseline therapies in patients with moderate COPD: a post hoc analysis of the CRYSTAL study. Int J Chron Obstruct Pulmon Dis. 2018;13:1229-1237. doi:10.2147/COPD.S159732

56. Anzueto AR, Kostikas K, Mezzi K, et al. Indacaterol/glycopyrronium versus salmeterol/fluticasone in the prevention of clinically important deterioration in COPD: results from the FLAME study. Respir Res. 2018;19(1):121. doi:10.1186/s12931-018-0830-z

57. Rogliani P, Calzetta L, Braido F, et al. LABA/LAMA fixed-dose combinations in patients with COPD: a systematic review. Int $J$ Chron Obstruct Pulmon Dis. 2018;13:3115-3130. doi:10.2147/ COPD.S170606

58. Alahmari AD, Kowlessar BS, Patel AR, et al. Physical activity and exercise capacity in patients with moderate COPD exacerbations. Eur Respir J. 2016;48(2):340-349. doi:10.1183/13993003.011052015 
59. Pitta F, Troosters T, Probst VS, Spruit MA, Decramer M, Gosselink R. Physical activity and hospitalization for exacerbation of COPD. Chest. 2006;129(3):536-544. doi:10.1378/chest.129.3.536

60. Garcia-Aymerich J, Lange P, Benet M, Schnohr P, Antó JM. Regular physical activity reduces hospital admission and mortality in chronic obstructive pulmonary disease: a population based cohort study. Thorax. 2006;61(9):772-778. doi:10.1136/thx.2006. 060145

61. Jones GL. Quality of life changes over time in patients with chronic obstructive pulmonary disease. Curr Opin Pulm Med. 2016;22 (2):125-129. doi:10.1097/MCP.0000000000000242

62. Beeh KM, Burgel PR, Franssen FME, et al. How do dual long-acting bronchodilators prevent exacerbations of chronic obstructive pulmonary disease? Am J Respir Crit Care Med. 2017;196(2):139-149. doi:10.1164/rcem.201609-1794CI

63. Ariel A, Altraja A, Belevskiy A, et al. Inhaled therapies in patients with moderate COPD in clinical practice: current thinking. Int $J$ Chron Obstruct Pulmon Dis. 2017;13:45-56. doi:10.2147/COPD. S145573
64. Wedzicha JA, Banerji D, Chapman KR, et al. Indacaterol-glycopyrronium versus salmeterol-fluticasone for COPD. $N$ Engl J Med. 2016;374(23):2222-2234. doi:10.1056/NEJMoa1516385

65. Boehringer Ingelheim. FDA approves Stiolto ${ }^{\circledR}$ Respimat $^{\circledR}$ supplemental New Drug Application (sNDA) to add data on COPD exacerbation reduction. Available from: https://www.boehringer-ingelheim. us/press-release/fda-approves-stiolto-respimat-supplemental-newdrug-application-snda-add-data-copd. Accessed November 9, 2018.

66. Sievi NA, Brack T, Brutsche MH, et al. Accelerometer- versus questionnaire-based assessment of physical activity and their changes over time in patients with COPD. Int $J$ Chron Obstruct Pulmon Dis. 2017;12:1113-1118. doi:10.2147/COPD.S130195

67. Thyregod M, Bodtger U. Coherence between self-reported and objectively measured physical activity in patients with chronic obstructive lung disease: a systematic review. Int J Chron Obstruct Pulmon Dis. 2016;11:2931-2938. doi:10.2147/COPD.S116422

68. Concato J, Shah N, Horwitz RI. Randomized, controlled trials, observational studies, and the hierarchy of research designs. $N$ Engl J Med. 2000;342(25):1887-1892. doi:10.1056/NEJM200006223422507

International Journal of Chronic Obstructive Pulmonary Disease

\section{Dovepress}

\section{Publish your work in this journal}

The International Journal of COPD is an international, peer-reviewed journal of therapeutics and pharmacology focusing on concise rapid reporting of clinical studies and reviews in COPD. Special focus is given to the pathophysiological processes underlying the disease, intervention programs, patient focused education, and self management protocols. This journal is indexed on PubMed Central, MedLine and CAS. The manuscript management system is completely online and includes a very quick and fair peer-review system, which is all easy to use. Visit http://www.dovepress.com/testimonials.php to read real quotes from published authors. 